\title{
Flow of Binary and Tertiary Mixtures of Waxes
}

\author{
R. G. CRAIG, J. D. EICK, ${ }^{*}$ and F. A. PEYTON \\ University of Michigan, School of Dentistry, Ann Arbor, Michigan
}

\section{SYNOPSIS IN INTERLINGUA}

Le Fiuxo de Mixturas Binari e Tertiari de Cera.-Esseva constatate que le fluxo es un plus sensibile proprietate que le expansion thermic pro le studio del differentias inter varie mixturas de cera. Le fluxo de plure lots del mesme cera revelava significative differentias, indicante que un sensible test-como le determination del proprietates del fluxo-debe esser usate in seliger cera pro objectivos de recerca. Le addition de cera de carnauba a cera paraffinic resultava in un reduction del fluxo e un augmento del temperatura de transition al qual un augmento marcate in le fluxo esseva observate. Le addition de cera de ape a cera parafinic reduceva le fluxo solo levemente. Le fluxo de mixturas tertiari de ceras non poteva esser predicite a base del fluxo de mixturas binari.

The flow of wax subjected to a fixed load at a specified temperature is a critical property if the wax is to be used as a component of a dental inlay or casting wax. The flow of natural waxes that are used in the preparation of dental waxes was reported by Craig, Eick, and Peyton. ${ }^{1}$ Dental waxes normally are mixtures of waxes with some oils and resins, and the influence of these components on the flow of the wax is of primary importance.

Ellis $^{2,3}$ has published melting point values and melting point curves for binary mixtures of wax, and Koch, Hable, and Wrangell ${ }^{4}$ have reported the melting points of binary and tertiary mixtures of commercial waxes. Koch and Concetta ${ }^{5}$ have determined the influence of composition on the specific gravity of binary mixtures of wax. These studies, however, are the extent of the information available in the literature related to the important problem of the influence of component waxes on the properties of wax mixtures.

The three major types of natural waxes used in dental waxes are (1) paraffin or microcrystalline waxes, (2) plant or ester waxes such as carnauba, and (3) beeswax. Unfortunately, in the preparation of commercial dental waxes, considerable variation occurs in the various batches of natural

This investigation was supported by USPHS research grant DE-01234 from the National Institute of Dental Research, National Institutes of Health, Bethesda, Md.

Received for publication August 9, 1965.

* Present address, A.D.A. Research Division, National Bureau of Standards, Chicago, Ill. waxes. The purpose of this study was first to determine the variation expected in different batches of natural waxes and then, with typical batches of paraffin, carnauba, and beeswax, to study the influence of composition on the flow of binary and tertiary mixtures at various temperatures.

\section{Materials and Methods}

Four different lots each of paraffin wax (fully refined; melting point, 128 to $130^{\circ} \mathrm{F}$.), beeswax (refined yellow U.S.P.) and carnauba wax (refined pure No. 1 yellow) were used in the study. $\uparrow$ The per cent flow of each lot of wax was determined at two temperatures in accordance with the American Dental Association Specification No. 4 for dental inlay casting wax. ${ }^{6}$ The linear thermal expansion of the lots of paraffin wax was measured at 20 to $34^{\circ} \mathrm{C}$. as described by Craig and others, ${ }^{1}$ and the per cent flow was determined at 28 and $31^{\circ} \mathrm{C}$. The flow of beeswax was obtained at 34 and $40^{\circ} \mathrm{C}$., and the thermal expansion was measured at 20 to $50^{\circ} \mathrm{C}$. Carnauba wax was tested for flow at 75 and $77.5^{\circ} \mathrm{C}$. and the thermal expansion was evaluated between 20 and $50^{\circ} \mathrm{C}$.

Each lot of wax was divided into eight equal parts, and a portion was melted from each to prepare the specimens for flow and thermal expansion determinations. When the flow tests were conducted, test specimens were chosen at random from the total

$\dagger$ Lot numbers 193,274,303, and 319, paraffin; 1788,2170 , 2183 , and 2247 , beeswax; and B-1845-6, B-1845-5, B-1956, and B-2318, carnauba. Ross Company, Jersey City, N.J. 
group of specimens. Using data from a previous investigation ${ }^{1}$ and choosing to have a 10 per cent error on either side of the mean, it was found that a maximum of seven thermal expansion tests and six flow test values were necessary to obtain a 95 per cent confidence level. These numbers were calculated as follows:

Number of samples

$=\left(\frac{\text { confidence level } \times \text { standard deviation }}{10 \text { per cent of the mean }}\right)^{2}$.

The experimental data were statistically analyzed, using Duncan's multiple range test ${ }^{7}, 8$ for ranking the means and determining which of the four lots were significantly different. This test was superior to using only a single factor analysis of variance, which would indicate only whether there was a significant difference between the four means of each batch of wax when tested under the same conditions and would not indicate which mean or means were different.

The lots of waxes that were not found to be significantly different were combined and the per cent flow of the following binary mixtures was determined between $27^{\circ}$ and $45^{\circ}$ C.: $2.5,10.0$, and 25.0 per cent carnauba wax in paraffin wax, and 2.5, 10.0, and 25.0 per cent beeswax in paraffin wax. The following tertiary mixtures also were tested: $2.5,10.0$, and 25.0 per cent carnauba wax added to a binary mixture of 10 per cent beeswax and 90 per cent paraffin wax. The per cent flow was determined with a micrometer flow tester* at a constant load of 2,000 Gm., and the flow was recorded at half-minute intervals for 10 minutes. The thermal expansion curves were determined as previously described. ${ }^{1}$

\section{Results}

The coefficients of thermal expansion and the per cent of the various batches of wax are listed in Tables 1 and 2. The means were ranked using Duncan's multiple range test. The vertical lines to the right of the mean values indicate groupings that were significantly different at the 95 per cent confidence level. For example, the vertical line extending from the high to low values of the coefficient of thermal expansion of the four

* B. C. Ames Company, Waltham, Mass. batches of paraffin wax at 20.0 to $26.3^{\circ} \mathrm{C}$. showed that the property was the same within statistical limits. The linear coefficient of thermal expansion values indicated significant differences only in the batches of beeswax when tested at 37.9 to $50.0^{\circ} \mathrm{C}$.

The per cent flow was more sensitive to difference in batches than the thermal expansion. The per cent flow of the batches of paraffin waxes 193,303 , and 319 at $28^{\circ} \mathrm{C}$. were alike, and batch 274 was significantly different. The per cent flow of paraffin waxes at $31^{\circ} \mathrm{C}$. showed batches 193 and 274 and batches 303 and 319 were alike, but the two pairs were significantly different. The greatest variation in flow properties occurred with the batches of beeswax where all the batches were significantly different at 34 or $40^{\circ} \mathrm{C}$.

On the basis of the thermal expansion and flow of the waxes, binary and tertiary mixtures were prepared from paraffin wax batch 319 , beeswax batch 2247 , and carnauba wax batch B-2318.

Flow curves for binary mixtures of paraffin and carnauba wax were determined at many temperatures between 27 and $45^{\circ} \mathrm{C}$. Typical curves are shown for paraffin and paraffin containing 2.5, 10.0, and 25.0 per cent carnauba wax (Fig. $1 \mathrm{~A}-\mathrm{D}$ ). In all instances, the rate of flow was most rapid immediately after the initial application of the load. After 1 to 4 minutes, the rate of flow decreased. At $28^{\circ} \mathrm{C}$., the per cent flow was small for all samples and was an inverse function of the concentration of carnauba wax. The binary mixture of 2.5 per cent carnauba wax and 97.5 per cent paraffin wax flowed extensively at $31^{\circ} \mathrm{C}$. and the mixtures containing 10.0 and 25.0 per cent carnauba wax flowed little. At $37.5^{\circ} \mathrm{C}$, or oral temperature, only the binary mixture containing 25.0 per cent carnauba wax showed substantial resistance to flow, but at $43.0^{\circ} \mathrm{C}$. even this mixture flowed about 70 per cent after 10 minutes.

The flow of the binary mixtures of paraffin and carnauba wax at all temperatures studied is summarized in Figure 2, which shows the per cent flow after being subjected to 27 to $45^{\circ} \mathrm{C}$. for 10 minutes at a load of $2,000 \mathrm{Gm}$. In each sample of wax there is a transition temperature which, if exceeded, results in distinct changes in flow properties. The addition of carnauba to 
TABLE 1

THERMAL EXPANSION OF BATCHES OF WAX

\begin{tabular}{|c|c|c|c|}
\hline Wax & $\begin{array}{c}\text { Temperature } \\
\text { Range } \\
\text { (C.) }\end{array}$ & Lot. No. & $\begin{array}{l}\text { Mean Linear } \\
\text { Coefficient of } \\
\text { Thermal } \\
\text { Expansion } \\
\left(\times 10^{-6}\right)\end{array}$ \\
\hline \multirow[t]{8}{*}{ Paraffin } & \multirow[t]{4}{*}{$20.0-26.3$} & 319 & 329 \\
\hline & & 303 & 317 \\
\hline & & 274 & 310 \\
\hline & & 193 & 310 \\
\hline & \multirow[t]{4}{*}{$26.3-34.0$} & 319 & 1424 \\
\hline & & 303 & 1410 \\
\hline & & 274 & 1360 \\
\hline & & 193 & 1329 \\
\hline \multirow{8}{*}{ Beeswax } & \multirow{4}{*}{$20.0-37.9$} & 1788 & 311 \\
\hline & & 2170 & 299 \\
\hline & & 2183 & 298 \\
\hline & & 2247 & 296 \\
\hline & \multirow[t]{4}{*}{$37.9-50.0$} & 1788 & 957 \\
\hline & & 2247 & 832 \\
\hline & & 2170 & 706 \\
\hline & & 2183 & 647 \\
\hline \multirow[t]{4}{*}{ Carnauba } & \multirow[t]{4}{*}{$20.0-50.0$} & B-1845-C & 157 \\
\hline & & B-1956 & 154 \\
\hline & & B-1845-S & 150 \\
\hline & & B-2318 & 148 \\
\hline
\end{tabular}

TABLE 2

FLOW OF VARIOUS Batches OF WAX

\begin{tabular}{|c|c|c|c|}
\hline Wax & $\begin{array}{l}\text { Temperature } \\
\text { (C.) }\end{array}$ & Lot No. & $\%$ Flow \\
\hline \multirow[t]{8}{*}{ Paraffin } & \multirow[t]{4}{*}{28.0} & 274 & 3.91 \\
\hline & & 193 & 3.0 \\
\hline & & 303 & \\
\hline & & 319 & 2.8 \\
\hline & \multirow[t]{4}{*}{31.0} & 193 & 62.3 \\
\hline & & 274 & 62.1 \\
\hline & & 303 & 58.8 \\
\hline & & 319 & 57.9 \\
\hline \multirow[t]{8}{*}{ Beeswax } & \multirow[t]{4}{*}{34.0} & 2183 & 14.2 \\
\hline & & 2170 & 2.8 \\
\hline & & 2247 & 1.2 \\
\hline & & 1788 & 0.6 \\
\hline & \multirow[t]{4}{*}{40.0} & 2170 & 77.9 \\
\hline & & 2183 & 77.2 \\
\hline & & 2247 & 75.8 \\
\hline & & 1788 & 72.6 \\
\hline \multirow[t]{4}{*}{ Carnauba } & \multirow[t]{4}{*}{75.0} & B-1956 & 1.1 \\
\hline & & B-1845-S & 0.9 \\
\hline & & B-2318 & 0.9 \\
\hline & & B-1845-C & 0.8 \\
\hline \multirow{4}{*}{$\because$} & \multirow[t]{4}{*}{77.5} & B-1845-C & 74.1 \\
\hline & & $\mathrm{B}-1845-\mathrm{S}$ & 72.6 \\
\hline & & B-2318 & 70.3 \\
\hline & & B-1956 & 69.6 \\
\hline
\end{tabular}



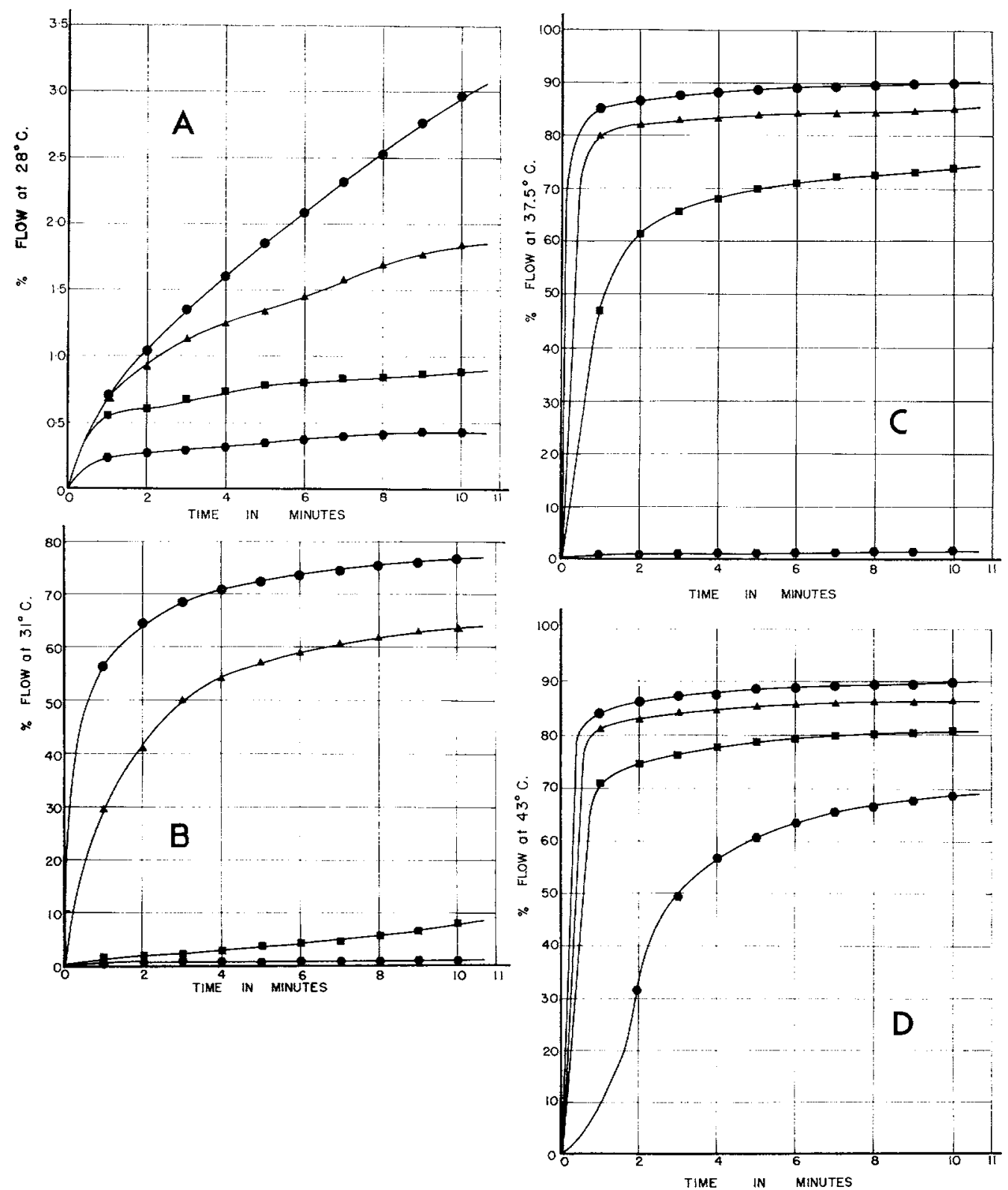

Fig. 1.-Flow of paraffin wax and binary mixtures of paraffin and carnauba wax as a function of time at (A) $28^{\circ} \mathrm{C}$., (B) $31^{\circ} \mathrm{C}$, (C) $37.5^{\circ} \mathrm{C}$, and (D) $43^{\circ} \mathrm{C}$. Circles $=100$ per cent paraffin, triangles $=2.5$ per cent carnauba wax and 97.5 per cent paraffin, squares $=10$ per cent carnauba wax and 90 per cent paraffin, and hexagons $=25$ per cent carnauba wax and 75 per cent paraffin. 
paraffin wax strongly influenced the transition temperature, for example, the addition of 25.0 per cent carnauba wax to paraffin wax increased the transition temperature from $28^{\circ} \mathrm{C}$. to about $39^{\circ} \mathrm{C}$.

The flow of mixtures of paraffin and beeswax is not shown in the form of a figure because, in concentrations up to 25 per cent, beeswax had little influence on the flow of paraffin. An increase in the transition temperature of only $0.6^{\circ} \mathrm{C}$. was observed from the addition of 25 per cent beeswax.

The flow properties of tertiary mixtures of paraffin, carnauba, and beeswax are shown (Fig. 3). Increasing the concentration of carnauba wax with respect to the mixture of 90 per cent paraffin and 10 per cent beeswax had the same general effect on the flow properties as when binary mixtures of paraffin and carnauba alone were studied. The mixture of 25 per cent carnauba and 75 per cent of the mixture of paraffin and beeswax flowed more at comparable temperatures than did the mixture of 25 per cent carnauba and 75 per cent paraffin. In general, the same effect, but to a lesser extent, was observed for the other tertiary mixtures having lower concentrations of carnauba wax.

\section{Discussion}

The flow of waxes is a more critical measure of small differences between batches of the same waxes than is the coefficient of thermal expansion. This result should be anticipated, since small amounts of lowmolecular-weight components, such as oils, will change the flow substantially by a plasticizing action but will have little effect on the thermal expansion. The comparison of physical properties of mixtures of wax from various laboratories probably will show considerable variation unless batches are used which have comparable transition temperatures indicated by flow or another sensitive test.

The high-melting-point carnauba wax has a pronounced effect on the per cent flow of

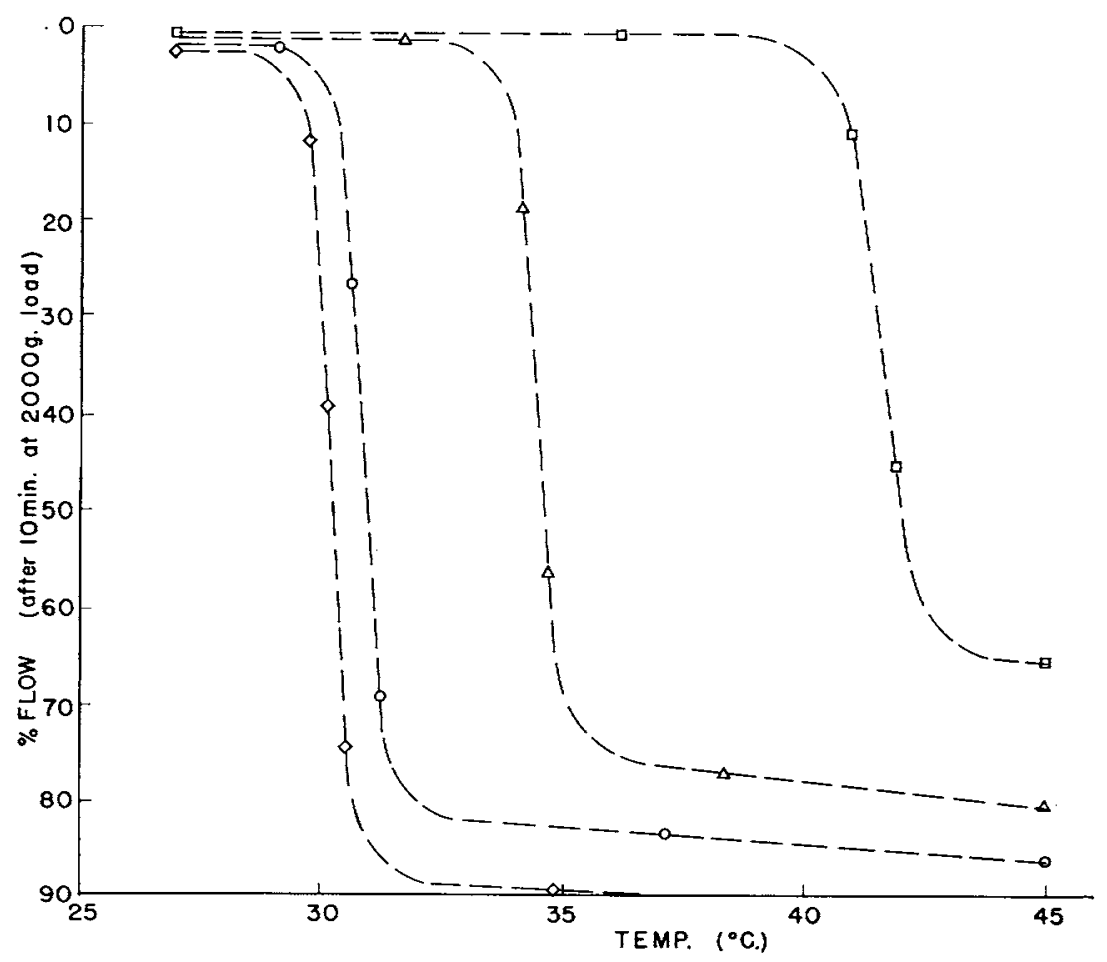

Fig. 2.-Flow of paraffin wax and binary mixtures of paraffin and carnauba wax after 10 minutes at 27 to $45^{\circ} \mathrm{C}$. Diamonds $=100$ per cent paraffin, circles $=2.5$ per cent carnauba wax, triangles $=10.0$ per cent carnauba wax, and squares $=25.0$ per cent carnauba wax. 
paraffin wax and therefore is useful in adjusting the flow of wax mixture for a particular application in dentistry. The high resistance to flow of carnauba wax is attributed to the presence of the polar ester groups and the resulting intermolecular attraction. The melting points of mixtures of paraffin and carnauba wax as measured by the capillary tube method ${ }^{1}$ indicate little increase in melting point of paraffin as a result of adding carnauba wax up to concentrations of 25 per cent. Partial melting was observed at the normal melting point of paraffin, as indicated by a change from an opaque to a transluscent appearance, and the melting was completed at a temperature near the value for carnauba wax. This melting point information is in contradiction to that of Ellis $^{2,3}$ and Koch, Hable, and Wrangell, ${ }^{4}$ who used a method where the melting temperature was measured by observing when a small disk of wax fell off a brass plate submerged in a water bath. This test involves some aspects of flow, which may account for the observation that addition of 25 per cent carnauba to paraffin wax increased the melting point by about $30^{\circ} \mathrm{C}$. This observation would agree with the flow measurements but not the capillary tube melting points.

The observation that the flow properties of the tertiary mixtures are not additive is of particular interest. The lower transition temperature of the mixture containing 25 per cent carnauba wax with beeswax and paraffin wax compared with a binary mixture of 25 per cent carnauba and 75 per cent paraffin wax is of particular interest, since the effect of adding beeswax to paraffin wax is to raise the transition temperature slightly. A comparison of the means of the transition temperatures indicates there is significant difference at the 99 per cent confidence level. A possible explanation for these observations is an increase in the mutual solubility of paraffin and carnauba wax,

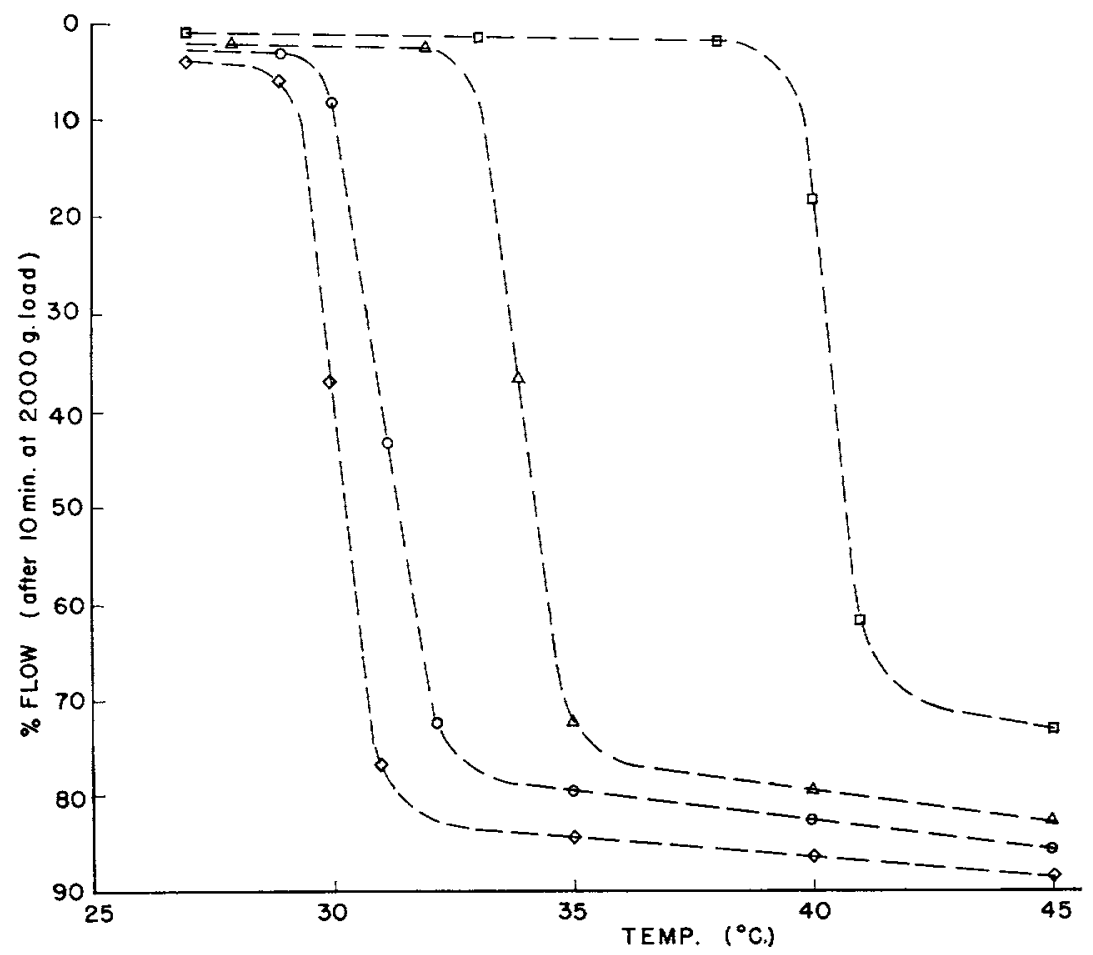

Frg. 3.-Flow of tertiary mixtures of carnauba wax with beeswax and paraffin after 10 minutes at 27 to $45^{\circ} \mathrm{C}$. Diamonds $=90$ per cent paraffin and 10 per cent beeswax, circles $=2.5$ per cent carnauba wax and 97.5 per cent $\operatorname{mix}$ ( 90 per cent paraffin and 10 per cent beeswax), triangles $=10$ per cent carnauba wax and 90 per cent mix ( 90 per cent paraffin and 10 per cent beeswax), and squares $=25$ per cent carnauba and 75 per cent mix ( 90 per cent paraffin and 10 per cent beeswax). 
since beeswax consists of considerable quantities of hydrocarbon as well as ester molecules, while paraffin wax is essentially hydrocarbon and carnauba wax is primarily ester in nature. The effect of this increased solubility would be to interfere with the matrix of high-melting-point carnauba wax and reduce the intermolecular attraction between ester groups, thus reducing the transition temperature and increasing the flow. Examination of these mixtures by using differential thermal analysis and thermogravimetric analysis should provide information to help integrate these observations.

\section{Summary}

The property of flow was used to study binary and tertiary mixtures of wax, since it was more sensitive to differences between batches of wax than the thermal expansion. The flow of various batches of the same wax showed that significant differences may exist between batches, and some sensitive test should be used in the selection of waxes for research studies.

Addition of carnauba to paraffin wax re- sulted in a reduction of the flow and an increase in the transition temperature when a definite increase in flow was observed. Addition of beeswax to paraffin wax decreased the flow only slightly. The flow of tertiary mixtures of the waxes could not be predicted on the basis of the flow of binary mixtures.

\section{References}

1. Craig, R. G., Eick, J. D., and Peyton, F. A. The Properties of Natural Waxes Used in Dentistry, J. dent. Res., 44:1308-16, 1965.

2. Ellis, W. J. The Melting-point Curves of Some Binary Wax Mixtures, J. Council Sci. Ind. Res. (Australia), 16:179-84, 1943.

3. ㄴ._. Melting Points II. Melting Points of Binary Wax Mixtures, Petroleum (London), 8:115, 1945.

4. Koch, J. R., Hable, G. J., and Wrangeld, Lewis. Melting-point Studies of Binary and Trinary Mixtures of Commercial Waxes, Ind. Eng. Chem., Anal. Ed. 10:167-68,1938.

5. Koch, J. R., and Concetta, Sister M. The Effect of Composition on The Specific Gravity of Binary Mixtures, Kentucky Acad. Sci. Trans., 13:104-10, 1950:

6. American Dental Association. Guide to Dental Materials, ed. 2. Chicago, American Dental Association, 1964, p. 95-98.

7. Duncan, D. B. Multiple Range and Multiple F Tests, Biometrics, 11:1-42, 1955.

8. Federer, W. T. Experimental Design, New York, Macmillan Co., 1955. 